\title{
EDITORIAL: 20 ANOS DE PRINCIPIA DEDICADO À MEMÓRIA DO PROF. OSWALDO PORCHAT
}

Neste ano de 2017, celebramos os 20 anos da revista Principia. Alegramo-nos pelo sucesso na realização do $X$ Simpósio Internacional Principia, mas também lamentamos a perda de nosso primeiro editor, o Professor Oswaldo Porchat de Assis Pereira da Silva, que veio a falecer no último dia 15 de outubro. Porchat foi Professor Emérito da USP e da Unicamp, onde foi um dos fundadores do Departamento de Filosofia e do Centro de Lógica e Epistemologia (CLE). Nós, editores de Principia, orgulhamo-nos de dar continuidade ao trabalho deste grande filósofo brasileiro.

Este editorial tem o objetivo de contar um pouco da história da revista e, assim, entender seu presente. Para isso, entrevistamos um de seus fundadores, o Professor Luiz Henrique de Araújo Dutra. Luiz Henrique, atualmente Professor Titular na UFSC, sucedeu Oswaldo Porchat como editor responsável (a função que hoje se chama editor executivo) em 2005 e ficou no cargo até 2015. Ainda hoje, o Professor Luiz Henrique integra o Comitê Editorial da revista, apoiando e auxiliando, com toda a sua experiência, o trabalho dos demais editores. Dedicamos este editorial e esta entrevista à memória do Professor Porchat. Esperamos com isso contribuir para contar uma história que ele ajudou a construir.

$* * *$

Q: A revista foi fundada em 1997. Qual era a motivação naquela época?

LHAD: A principal motivação para criar a revista foi haver no Brasil uma revista filosófica voltada para a área de epistemologia especificamente, uma revista de nível internacional que publicasse artigos não apenas em português, mas em inglês, francês e espanhol. De fato, a revista foi parte de um projeto maior que tínhamos. As outras duas partes importantes desse projeto eram a pós-graduação em filosofia na UFSC e o NEL (Núcleo de Epistemologia e Lógica), cujo objetivo seria não apenas o de publicar a revista, mas também de promover atividades acadêmicas diversas, como vieram a ser anos depois os simpósios Principia. A pós-graduação em filosofia começou no mesmo ano de 1997, com mestrado e apenas a área de concentração em epistemologia. Além do Prof. Alberto Cupani, que foi o primeiro coordenador do programa, e de mim mesmo, também faziam parte do grupo de nosso departamento que formava a área de epistemologia os seguintes professores: Sara Albieri, Renato Machado, Marco Antonio Franciotti, Cezar Augusto Mortari, Gustavo Caponi e Antônio Mariano Coelho.

Q: E como foi a participação do Professor Porchat?

Principia 21(2): 159-162 (2017).

Published by NEL — Epistemology and Logic Research Group, Federal University of Santa Catarina (UFSC), Brazil. 
LHAD: Oswaldo Porchat tinha sido professor ou orientador de alguns de nós e era uma referência acadêmica importante na área não só por sua atuação na Unicamp, como fundador tanto do CLE quanto do próprio departamento de filosofia de lá, mas também pela atuação que então ele tinha, com importantes realizações nos estudos sobre ceticismo. Eu era muito próximo dele e fazia parte na época do grupo que ele liderava sobre essa temática, grupo que acabou gerando dois atuais GTs da ANPOF. Fora o Professor Cupani, que era já um pesquisador mais experiente, os demais de nosso grupo eram iniciantes e nós queríamos um nome de peso para liderar a revista, mas alguém que tivesse uma real relação intelectual e acadêmica conosco. Foi assim que resolvemos convidar o Professor Porchat para ser o editor da revista. Ele foi um pouco relutante, pois não queria assumir encargos burocráticos, mas aceitou em virtude do apoio que daria ao nosso grupo, cujo potencial ele reconhecia. Os diversos editores assistentes que a revista teve desde então o liberaram das tarefas mais burocráticas.

Q: Quem eram os outros editores?

LHAD: Durante o período em que o Professor Porchat foi o editor responsável pela revista, foram editores assistentes Alberto Cupani, Cezar Mortari e eu mesmo, em períodos distintos. Quando passei a ser o editor responsável pela revista, em 2005, o Prof. Mortari continuou a ser editor assistente e outros foram se somando a esse grupo, como Jaimir Conte, Jonas Becker Arenhart e Ivan F. da Cunha.

Q: Quais as principais dificuldades que a revista enfrentou?

LHAD: Até o advento da publicação eletrônica, a principal dificuldade da revista era a falta de recursos financeiros para publicar em papel. E uma dificuldade importante que temos desde o início é a falta de pelo menos um funcionário permanente que se dedique à revista. Isso se tornou menos dramático depois do início da publicação eletrônica, mas sobretudo em virtude da dedicação dos professores Mortari e Conte. No início, para viabilizar a publicação, procuramos a parceria com a Editora da UFSC, com a qual os primeiros números da revista foram publicados. Em pouco tempo, percebemos que essa parceria mais nos atrapalhava do que ajudava. Resolvia o problema financeiro, mas implicava uma série de imposições editoriais. De fato, a partir do momento que deixamos a parceria com a editora e assumimos inteiramente a publicação, as coisas melhoraram. Tivemos ainda de procurar apoio financeiro ocasional, mas tudo ficou mais fácil a partir da publicação eletrônica.

Q: Como surgiu a iniciativa de realizar os simpósios?

LHAD: A história dos simpósios começa muito antes e está relacionada com os Encontros de Filosofia Analítica, que foram uma iniciativa da Profa. Maria Cecília Carvalho, da PUC-Campinas. Ela organizou dois desses encontros, que foram muito bem sucedidos. Nós assumimos a organização dos outros dois encontros nessa série que houve. Depois as pessoas que assumiram a organização do quinto encontro não conseguiram fazê-lo.

Principia 21(2): 159-162 (2017). 
Com isso, tivemos a ideia de iniciar uma nova série de encontros ligados ao NEL e à Principia, mas deixando a antiga denominação, para não provocar desentendimentos. Mas imediatamente os simpósios Principia, que tinham sido concebidos para serem encontros menores, ganharam aceitação geral e foram encarados como a continuidade daqueles encontros. O fato é que os simpósios Principia se consolidaram ao longo dos anos como o principal encontro de filosofia no Brasil depois dos encontros da própria ANPOF, tendo também projeção internacional.

Q: Na sua opinião, qual a maior contribuição de Principia à comunidade filosófica brasileira?

LHAD: É forçoso compararmos Principia com outra revista filosófica no Brasil, bem mais antiga, e bem consolidada, a Manuscrito. Essa comparação é pertinente para destacarmos o fato de que, embora seja muito mais nova, Principia atingiu imediatamente o mesmo nível de excelência da revista da Unicamp, e, de fato, é hoje mais reconhecida internacionalmente como uma referência latino-americana de publicação filosófica de alta qualidade. Assim, a principal contribuição de nossa revista é essa, isto é, ser a principal publicação filosófica brasileira em filosofia nos dias de hoje. Não é nenhum exagero dizermos isso, mesmo reconhecendo a qualidade de outras publicações da área, especialmente a Scientiae Studia, da USP.

Q: Quando comparamos o cenário acadêmico e filosófico em que surgiu a revista e a situação que temos hoje, que mudanças podemos notar?

LHAD: O que de mais importante mudou é que hoje temos uma comunidade filosófica não apenas numericamente muito maior, mas que conta com um nível de qualidade $e$ de reconhecimento internacional que não havia na última década do século passado. Isso mudou sobretudo graças à consolidação da pós-graduação em filosofia no Brasil de forma geral, processo para o qual contribuiu não apenas o nosso programa de pós, mas também, em grande medida, nossa revista e os simpósios Principia. A situação agora é muito melhor profissionalmente, pois deixamos de ser uma pequena comunidade filosófica periférica, dominada por pequenos grupos de poder, e passamos a ser uma grande comunidade de pesquisadores competentes, produtivos e reconhecidos, com múltiplas lideranças que, na maior parte das vezes, são de caráter eminentemente acadêmico, genuinamente filosófico.

Como dito acima, buscamos com essa entrevista registrar um pequeno retrato do passado e do presente de nossa revista. Esta edição comemorativa traz ainda seis artigos que compõem um retrato de nossa atividade atual e que, esperamos, podem contribuir para o futuro de nossos debates. Recebemos e publicamos os textos de seis dos conferencistas convidados ao $X$ Simpósio, incluindo o próprio Professor Luiz 
Henrique Dutra. Esses seis artigos lidam com o tema que escolhemos para o $X$ Simpósio, A Construção da Experiência. A escolha do tema deu-se por este ser um assunto que perpassa diversas áreas da filosofia e que adquire um papel central em muitas discussões da atualidade. As conferências principais do Simpósio trataram do tema a partir de pontos de vista e de abordagens variadas, contribuindo assim para o direcionamento da troca de ideias realizada no evento. Quem compareceu ao Castelmar Hotel em Florianópolis entre 14 e 17 de agosto de 2017 teve a oportunidade de presenciar debates profundos e abrangentes. Isso nos leva a concluir que nossa escolha de tema e de convidados foi acertada. Agradecemos a todos e todas que ajudaram no sucesso do X Simpósio Internacional Principia. E esperamos, para celebrar os 20 anos de Principia, que os seis artigos aqui publicados motivem ainda mais discussões.

Os artigos são os seguintes:

A Construção da Experiência Perceptiva. O que isso quer dizer?, por Gary Hatfield (University of Pennsylvania, EUA), traduzido por Ivan Ferreira da Cunha e Renato Cesar Cani a partir de uma contribuição original do Professor Hatfield.

Inferência Metafísica e a Experiência do Observável, por Anjan Chakravartty (University of Notre Dame, EUA), traduzido por Ivan Ferreira da Cunha e Raoni Wohrath Arroyo a partir de uma contribuição original do Professor Chakravartty.

Experience and Mathematical Knowledge [Experiência e Conhecimento Matemático], por Rodolfo Gaeta (Universidad de Buenos Aires, Universidad Nacional de Luján, Argentina).

A Experiência Perceptual na Perspectiva da Teoria da Percepção Direta, por Mariana C. Broens (Universidade Estadual Paulista, Brasil).

Intentionality and Continuity of Experience [Intencionalidade e Continuidade da Experiência], por André Leclerc (Universidade de Brasília, Brasil).

A beleza está nos olhos de quem a vê? A percepção de realidades abstratas, por Luiz Henrique de Araújo Dutra (Universidade Federal de Santa Catarina, Universidade de Brasília, Brasil).

Principia 21(2): 159-162 (2017). 